\title{
INTELLECTUAL COMPONENT OF GLOBAL LEADERSHIP
}

\author{
Iryna Kalenyuk ${ }^{1}$, Liudmyla Tsymbal ${ }^{2}$, Olena Grishnova ${ }^{3}$, Antonina Djakona ${ }^{4}$ \\ ${ }^{1}$ Prof. Dr. Kyiv National Economy University Named After Vadym Hetman. Address: 54/1 Prospect Peremogy \\ 03057 Kyiv, Ukraine.Tel. +38096 7505810.E-mail kalenuk@ukr.net \\ ${ }^{2}$ Prof. Dr. Kyiv National Economy University Named After Vadym Hetman. Address: 54/1 Prospect Peremogy \\ 03057 Kyiv, Ukraine. Tel. +38093 2395608. E-mail l.tsimbal@ukr.net \\ ${ }^{3}$ Prof. Dr., prof. of department of Enterprise Economics, Taras Shevchenko National University of Kyiv, Kyiv, \\ Ukraine.Tel.+380676030000.E-mail: grishnova@ukr.net \\ ${ }^{4}$ Assoc. Prof. Dr., Vice-rector, ISMA University. Address: 1 Lomonosova str., LV-1019, Riga, Latvia. Tel. \\ +371 20216469. E-mail: antonina.djakona@isma.lv
}

Received 09102020 10; Accepted 22012021

\begin{abstract}
The rapid intellectualization of economic activity in modern conditions actualizes the study of issues of countries' leadership, achieved with the help of intellectual factors. The article's purpose is to assess the intellectual leadership of countries based on the performance indicators of intellectual activity. The method of estimation of intellectual leadership is proposed, which provides three levels of evaluation based on the corresponding set of indicators. The three-step evaluation algorithm includes, firstly, the assessment of the intellectual potential of the resource potential, secondly, the consideration of the results of intellectual activity and, thirdly, the final results of economic activity. The second level indicators are the result of intellectual activity, the implementation of intellectual resources and at the same time, they become the basis for further intellectualization. The analysis of the performance indicators of the intellectual activity of the countries of the world made it possible to identify the composition and disposition of the world leaders (the USA is the leader by nine indicators, Japan and Germany are leading by six, South Korea, the United Kingdom, China and France - by 5, Switzerland and Canada - 4 indicators) and showed a high volatility of their ranks.
\end{abstract}

Key words: intellectual leadership, leadership, knowledge economy, intellect, human capital.

JEL Codes: I23, I25.

\section{Introduction}

In the context of the formation of the knowledge economy, the role of intelligence becomes key, it forms the basic preconditions and determines the nature and dynamics of global economic development. Achievement of leadership positions of various subjects in the modern complex world is possible only on the basis of intellectual factors. Taking into account the modern trends of informatization, digitalization, networking, and the growth of the mobility of the world countries, the development of intellectual potential in their national development strategies and the priority directions of building a knowledge economy are among them. The achievement of intellectual leadership depends not only on the development and spread of technology, but also on the ability of countries to cooperate in these new environments, taking into account the formation of global production chains and innovation space. Accordingly, the global landscape of intellectual leadership changes and transforms, and new players are emerging, and in their turn, continue this transformation and form new ties.

In general, intellectual leadership is understood as the achievement of high positions in the competition due to the high quality and intensity of the implementation of intellectual resources. The author's methodology for evaluating intellectual leadership involves: resources and final results levels. The availability of diversified intellectual resources is the first step in achieving intellectual leadership and, accordingly, the assessment of resource potential is the first step in identifying leadership positions in countries around the world.

Copyright (C) 2020. Published by Vytautas Magnus University. This is an open access article distributed under the terms of the Creative Commons Attribution Non-Commercial 4.0 (CC BY-NC 4.0) license, which permits unrestricted use, distribution, and reproduction in any medium provided the original author and source are credited. The material cannot be used for commercial purposes. 
At the same time, it is important to assess not only the availability of a certain resource potential, but also the results of its implementation. Therefore, the next important step is to evaluate the results of intellectual activity. In the system of structural and functional characteristics of the global intellectual space, it is expressed as a second-level leadership.

The article's purpose is to assess the intellectual leadership of countries based on the performance indicators of intellectual activity.

Research methods. The content of this study, scientific findings, conclusion and recommendations are based on the broad application of the systematic approach to the study of the phenomena. The following methods are used for achievement of the research goal: scientific literature review and modeling methods suggested quantitative empirical study to be performed in finding actual evidence for solutions of defined scientific problem. Descriptive statistical analysis and visualization methods were applied to organize the research results. In the article used the methodology of comparative analysis and assessment of the dynamics of key indicators of innovation activity of the leading countries of the world.

\section{Research results and discussion}

Intellectual leadership is formed on the basis of the results of intellectual activity and includes indicators reflecting educational, scientific, infrastructural and technological readiness for introduction of innovations and realization of intellectual potential. These indicators show both the results of intellectual activity and, in turn, can act as a resource or a necessary basis for the formation of new results of intellectual activity.

Educational-scientific indicators serve as both resources and results, but as a resource of a higher level, which is already a certain result. The group of educational-scientific indicators includes the number of world-class universities, the number of scientific and technical publications, the number of Nobel laureates. Infrastructure indicators primarily include opportunities for using technology for innovation development, in particular, the number of Internet users (percentage of population); number of users of mobile telephony (persons); number of mobile telephony users (per 100 people); number of fixed telephone users (persons); number of fixed telephone users (per 100 people); secured Internet servers; Secured Internet Servers (per million us.). The last group of indicators includes technological indicators, which include, in particular: the number of technical staff in R\&D; technical staff in R\&D (per 1 million of population); registration of trademarks (residents, non-residents and total number); high-tech exports ( $\$$ and $\%$ of total exports); ICT products and services (export and import); applications for industrial designs (residents and non-residents); patent applications (residents and non-residents).

The presence of world-class universities also shows the country's ability to build and develop its own intellectual potential, and, at the same time, shows the high efficiency of their intellectual activity. The assessment methodology of the universities is rather exact and includes a significant number of effective indicators, in particular, the quality of staff (the number of Nobel laureates working at the university), the quality of training (the number of graduates who received the Nobel Prizes), the level of quotations of researchers and academic efficiency. Key ratings for university performance indicate that the vast majority of these universities are concentrated in the United States and Europe. Thus, according to the Shanghai Academic Ranking of World Universities (ARWU), 16 of the top 20 universities are located in the United States of America (Academic ranking..., 2017).

The United States, Great Britain and Switzerland completely fill the TOP-20 list of universities in the world. This confirms the unconditional intellectual prevalence of these countries on the world stage. If we analyze the same indicators according to The Times Higher Education World University Rankings, we can note that the situation is not very different (World University..., 2017). In both ratings, the US leads by the number of world-class universities and this leadership is indisputable. However, Germany, Australia, the Netherlands and Canada are also ranked as leaders in this ranking. The gap between the first and second position is quite significant. In the leader country 
(USA), the number of world-class universities is more than four times higher than the number of such universities in Germany and the UK (they share the second position).

The next indicator is the number of Nobel laureates in the country, as this indicator is taken into account in many university rankings. Analyzing the number of Nobel laureates in countries around the world, it should be noted that this indicator is also significantly higher in the United States (Fig. 1)

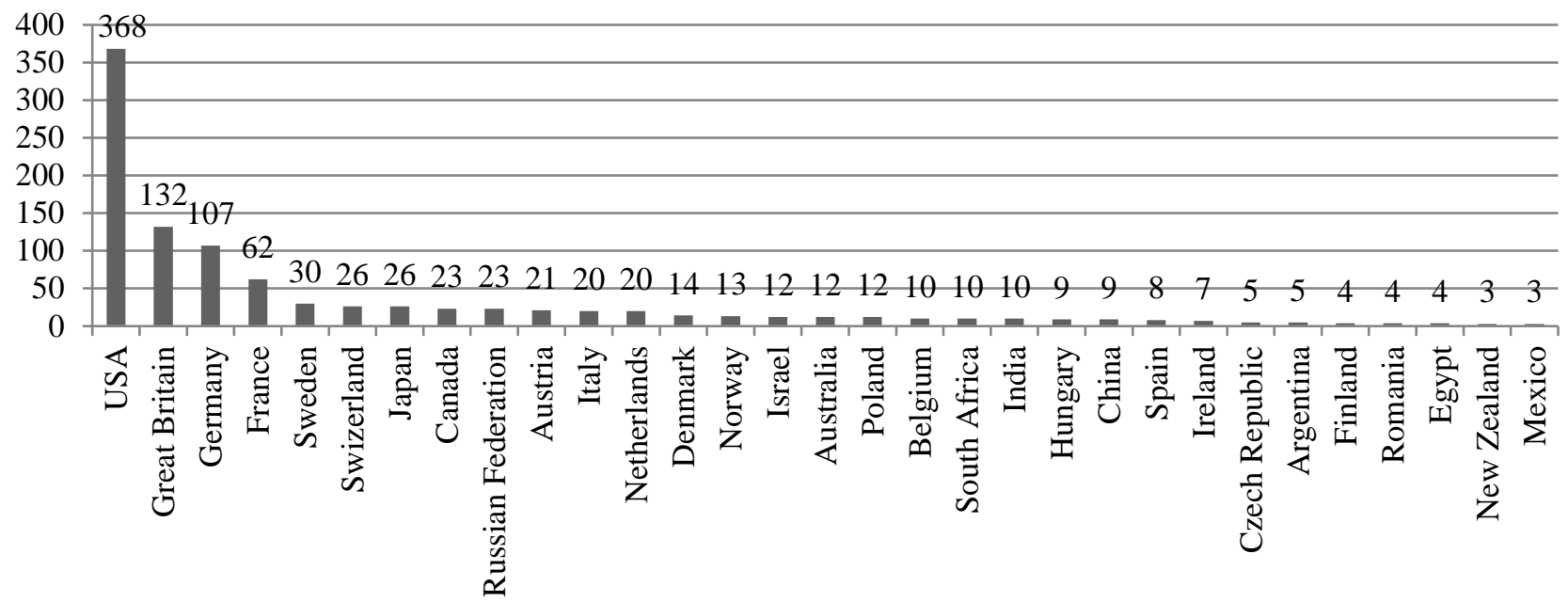

Figure 1. The ranking of countries by the total number of Nobel laureates, 2017 (TOP-30..., 2017)

The leadership of the United States is absolute and the number of Nobel laureates exceeds their number in Germany by 3 times. For instance, only in Harvard, 157 Nobel laureates work, which is more than in the whole Great Britain, which is in second position. And 116 of the 132 British laureates work in Cambridge (List of..., 2017). In total, 75 countries of the world have Nobel laureates and in 43 of them the number does not exceed 2 (including in Ukraine). The vast majority of Nobel laureates are concentrated in the United States and Europe.

The next important indicator is the number of scientific publications in the cited publications. Statistics shows that countries with a lower level of development in recent years have been actively increasing the number of publications in cited publications, which in turn affects the position of universities in global rankings. The highest number of publications per year in the world is in China. The Government of China adopted a focused strategy for innovation development, and one of the key indicators that were determined was to enter the TOP- 5 countries by the number of publications by 2020. In general, over the period from 2005, the number of publications scientists from China shows an increase of $158 \%$, India by $232 \%$, Chile by $168 \%$, Colombia by $534 \%$, Latvia by $178 \%$, Luxemburg by $475 \%$. The smallest gain is shown by the USA, only $7 \%$, while being at the 2nd position in the world in 2016. Moreover, since 2014, the number of publications in comparison with previous years is gradually decreasing (Number of publications..., 2016).

Thus, the leading China and the United States show a rather different dynamics. While the US keeps on a relatively stable level, China has significantly increased its performance since 2005 . At the same time, Japan, which occupied the third position in 2005, even reduced its performance by $7 \%$ and lost 3 positions in 2016. The third position in 2016 was taken by India, which for the specified period has increased its performance by $232 \%$. Germany and the United Kingdom show relatively slight increases of $24 \%$ and $14 \%$, respectively. It is worth noting that the gaps even in the top ten leaders are extremely high. The USA and China have figures of more than 400,000, Germany and India - more than 10,000, Japan and the United Kingdom have slightly more than 90,000, France, 
Italy and South Korea - more than 60,000. The values between the first and the tenth position by this indicator vary by more than 7 times.

Important indicators for supporting leadership are a group of infrastructure indicators that characterize the economy's readiness to expand ICT and access to communications. The growth in the number of mobile communication subscribers per 100 populations is at an extremely high pace in developing countries. The highest growth rates with a colossal increase are shown by India - $981 \%$ since 2005, China (226\%), Brazil (154\%), Colombia (138\%), Mexico (101\%), Ukraine (111\%), Chile (98\%), Hong Kong (92\%), and Poland (82\%). In general, the growth rate in the world is quite significant and amounts to $197 \%$ in the period from 2005 to 2016. For comparison, developed countries have an average growth rate of $49 \%$ (OECD indicator), while some of them have extremely low growth rates for a given period.

Similar trends in growth can be noted when analyzing the growth of personal Internet users, which from 2005 to 2016 increased to $45 \%$ of the global population, showing an increase of $191 \%$ over the period. According to the World Bank, more than $90 \%$ of Internet users are in Iceland, Luxembourg, Norway, Denmark, Great Britain, Japan, South Korea and the Netherlands. For this indicator, growth is no longer so univocal and concentrates only on developing countries. With it, the highest growth is observed in Ukraine, where the number of individual users increased by $1299 \%$, India (1137\%), China (524\%), Colombia (428\%), Russia (380\%), Turkey (277\%), Mexico (249\%), Israel (216\%), Brazil (189\%). The lowest growth was observed in Iceland (13\%), Norway (18\%), Denmark (17\%), the Netherlands (11\%), Sweden (6\%), Finland (18\%) and the United States $(12 \%)$ with the overall increase among OECD countries by $45 \%$ for the specified period (ICT index..., 2018).

The number of reliable Internet servers has a large growth rate, due to the development of Internet technologies in general and mobile communication technologies. The average growth in the world since 2010 is $1777 \%$, and in developed countries of OECD - 1593\%. The highest growth rates are demonstrated by such countries: more than 10,000\% growth is observed in Singapore (10,939\%), Chile (15,872\%), China (17,340\%), Russia (20,614\%), and Ukraine (31 841\%). Less than 1,000\% of the increase is demonstrated by Austria (975\%), New Zealand (978\%), Norway (834\%), Japan (981\%), and South Korea (582\%). However, an increasing in the number of secure Internet services over the period since 2010 is extremely active, indicating the spread of technologies and opportunities for their use (ICT index...., 2018).

Patent activity is one of the most prominent indicators, since the number of patents indicates the results of scientific and research activities. The absolute leaders of 2016 were China, the USA, Japan, South Korea, Germany, India, Russia, Canada, Australia and Brazil. The unconditional leader is China, exceeding the US index of almost 1 million patents, while demonstrating an increase of $1189 \%$ of registered by residents patents for the period from 2005 to 2016 . The highest growth rates are seen in the countries of Asia and Latin America, in particular, India (179\% increase), Singapore (181\%), Mexico (124\%), Colombia (450\%), Turkey (571\%), which proves the activation of residents in innovation activities (Patent applications..., 2016). During this period, most countries show a decline in non-resident activity. There are countries in which the activity of non-residents significantly exceeds the activity of residents, in particular, India, Brazil, Canada, Australia, Singapore, Mexico, Israel, New Zealand, Columbia, Chile, Hong Kong. Consistent leaders over the past decade have been the United States, Japan, and South Korea, by the number of patents registered both residents and non-residents, which. However, they were surpassed by China in 2011 (Fig. 2). 


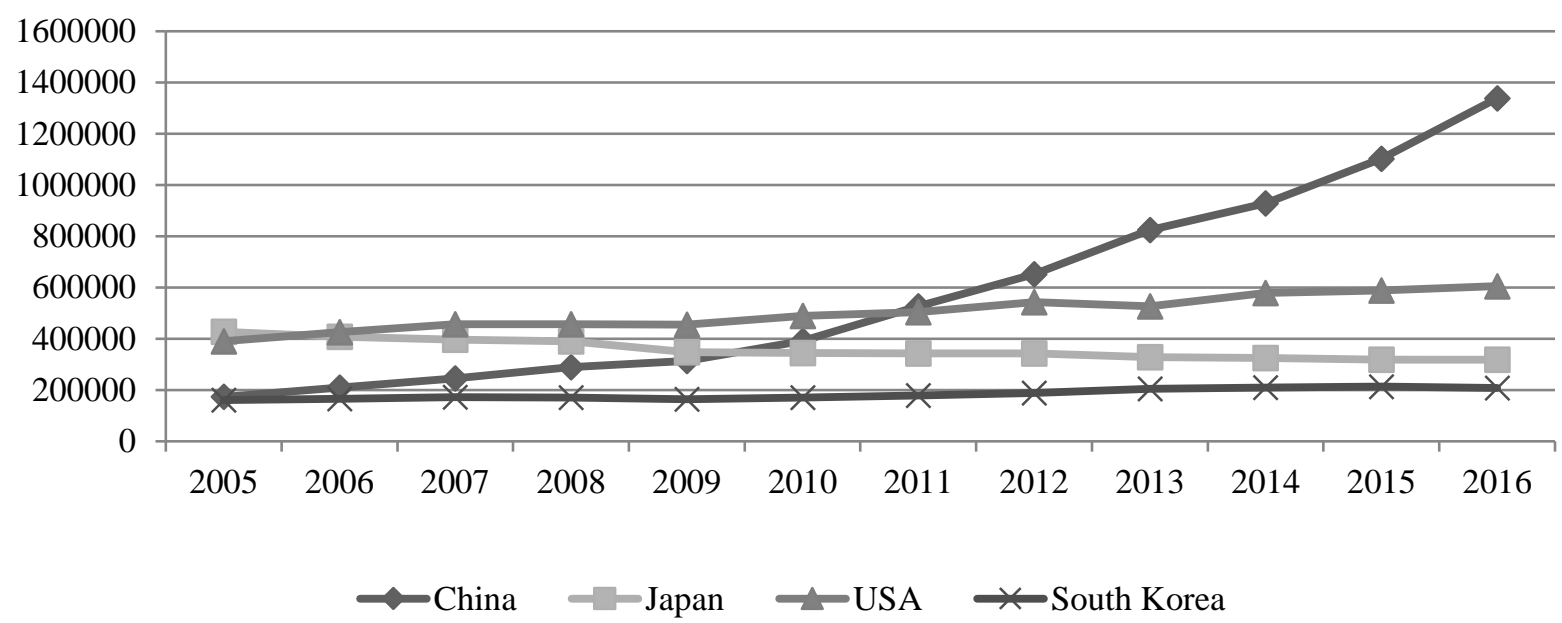

Figure 2. Dynamics of the total number of patents of the leading countries, 2005-2016 (Patent by country..., 2016)

In Japan, since 2005, the number of patents is gradually decreasing, while China is showing a sharp rise. The United States and South Korea are more moderate, but still the key trend is the growth of patent activity. The absolute outsiders by the number of patents are Estonia, Iceland, Slovakia, Ireland, Lithuania and Latvia, in the above countries the total number of patents does not exceed 300 and tends to decline.

The next indicator in this group is the number of applications for industrial designs submitted by both residents and non-residents. Industrial designs receive a patent for protection and may even act as patents for industrial designs. Leading by the number of applications for industrial designs is kept by China, South Korea, Germany, and others (Industrial design..., 2016).

One more indicator of this group is registration of trademarks. Its dynamics indicates the activation of industrial activity in the country and can serve as an indicator of the development of the global market. Similarly to previous figures reflecting the state of the market for intellectual property rights and its geographic structure, China is far ahead of all other countries in the world. There is a number of countries that have significantly reduced their quantifiable rates for this indicator between 2005 and 2016, in particular, Germany, Spain, Italy, Chile, Belgium, Poland, Sweden, Czech Republic, Austria, Greece, Hungary, Finland, Slovakia, Denmark, Lithuania, Iceland, Ireland, Latvia and Estonia.

In turn, among the countries that show positive dynamics, the leaders' group is emerging, and it is represented by China with a growth rate of $420 \%$, the United States with a rate of $150 \%$, India with a significant 345\%, Mexico (201\%), Great Britain (188\%), and Turkey (181\%). In general, not all of these countries are included in the TOP-10 by the total number of trademark registration (Trademark..., 2017).

One of the most important indicators of the effectiveness of intellectual activity is the actual realization of patent activity in practice, which is expressed with the volumes of high-tech products (production, export, import, ICT products and services). According to the reports of global organizations, it should be noted that the share of Asian countries in high-tech exports is constantly increasing and declined only in 2009 (Fig. 3) 


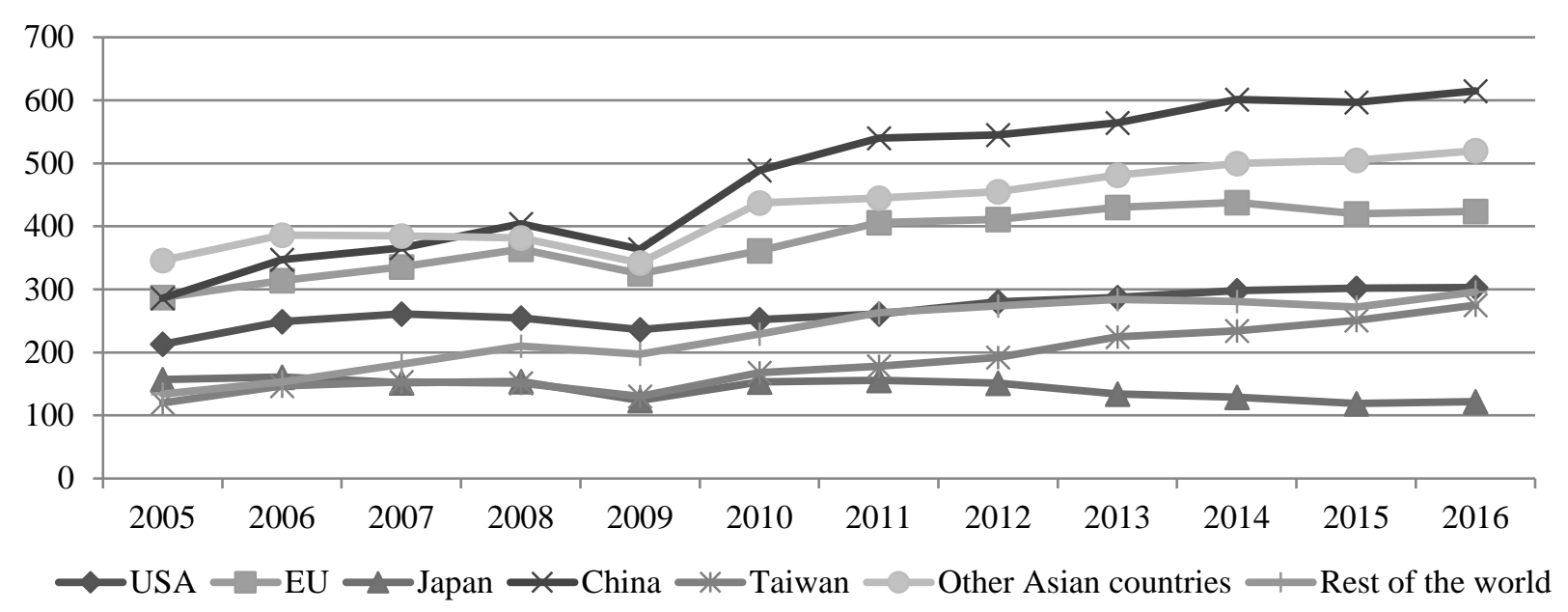

Figure 3. Exports of high-tech products by selected regions, countries, 2005-2016, mln. (Science..., 2018)

Only Japan has cut exports of high-tech goods for the selected period, and generally there is a gradual increase. Almost all selected countries reduced exports in 2009, due to the economic crisis of 2008, but quickly regained the exports level. Leaders are China, the countries of Asia and the EU. Among the countries studied in our sample, the highest level of exports of high-tech goods when converted to exports is general is demonstrated by Singapore, Ireland, Switzerland (Hightechnology..., 2016).

The share of exports in the vast majority of leading countries is gradually shrinking, which is explained not by the nominal decline in the export of high-tech goods, but by the growth of exports as a whole. The growth of exports of high-tech products in the above-mentioned TOP-10 is demonstrated only by Switzerland, France and Norway. The growth of this indicator is characteristic mainly for countries that had not very high figures in 2005 and, accordingly, have significant potential for building up. Those countries are Turkey, Chile, Slovenia, Poland, Colombia, Slovakia, Russia, Greece, Lithuania, Latvia, Belgium, Ukraine, but all these countries had less than $10 \%$ of exports of high-tech products in 2005. Thus, the maximum 223\% growth in Poland provides only $8.7 \%$ of exports of high-tech products of total exports in 2016.

Exports of high-tech products are a rather powerful trade flow, which is formed predominantly by highly developed countries. However, even highly developed countries have significant volumes of imports of high-tech products, which indicate the formation of certain centers of gravity. The US and the EU, despite a significant share of exports, are also leaders in terms of imports of high-tech products, which in turn indicates the specialization and the creation of global flows of such products and, accordingly, global markets.

Export-import flows are quite significant in all regions of the world, although the countries of Asia prevail. Asian preeminence is indisputable, followed by the countries of North America and the European Union. In general, Asian countries account for more than $60 \%$ of exports of high-tech goods. The world is divided between the key regions that ensure the formation of export flows. Asian countries generally import more than $10 \%$ than export, while in the countries of North America and the European Union, the foreign trade turnover of high-tech goods has a negative balance. Country analysis shows not only Asia's leadership in the global export of high-tech goods, but also China's leadership in particular (Patterns and..., 2018). Vietnam, China, Switzerland, Israel, Taiwan and Russia show the highest growth rates. The average growth rate for the sample of countries is $175 \%$ except of Vietnam, which shows a whopping $4167 \%$ since 2005.

Significant growth can be observed in the import of high-tech goods (Patterns and..., 2018). The average growth rate of imports of high-tech goods is $167 \%$, but China, South Korea, Mexico, India, Brazil and Turkey significantly exceed average growth rates. China and the United States show 
significant gap, which is at least 3 times higher than Japan's third position. Accordingly, the fourth position can be attributed to Germany, South Korea and Singapore, as their indicators are quite close to each other and they generally have similar dynamics. Mexico, France and the United Kingdom form the following group with indicators from $\$ 55$ billion to $\$ 61$ billion. The difference between leaders and followers is quite significant, and itself membership with the TOP-10 leading countries in this case does not indicate extremely high rates.

In addition to high-tech products, an important aspect of the country's activity is mediumhigh-tech products. According to this indicator, countries of Asia also lead. The growth here is much smaller than in high-tech products. Thus, the growth rate of exports in all countries of the world is $182 \%$, in North America the export growth rate is $157 \%$, the EU shows similar trends with an indicator of $152 \%$. The countries with the Middle East (289\%) and Africa (243\%) show the highest growth of exports of medium-high-tech products. Asian countries generally have indicators of growth of exports higher than the world and show 204\%, which means the actual doubling of exports of medium-high-tech goods. As for imports, the Middle East has a high growth rate, but much lower than exports (about 219\%). The highest growth rates of imports of medium-high-tech goods are shown by the countries of Africa, with an index of $230 \%$. Not very low indicator is in Central and South America - 196\%, the European Union and North America are at the bottom, with roughly the same rates $-157 \%$ and $156 \%$, respectively (Patterns and..., 2018).

In general, in all regions of the world, export-import operations of medium-high-tech products grew, due to increased trade volumes in general and the growth of the role of high value-added products in the processes of globalization and the gradual transition to the dominant technology in the new economy. If we analyze the dynamics of exports of medium-high-tech goods, we can note that in 2009, it significantly decreased in all countries (Fig. 4)

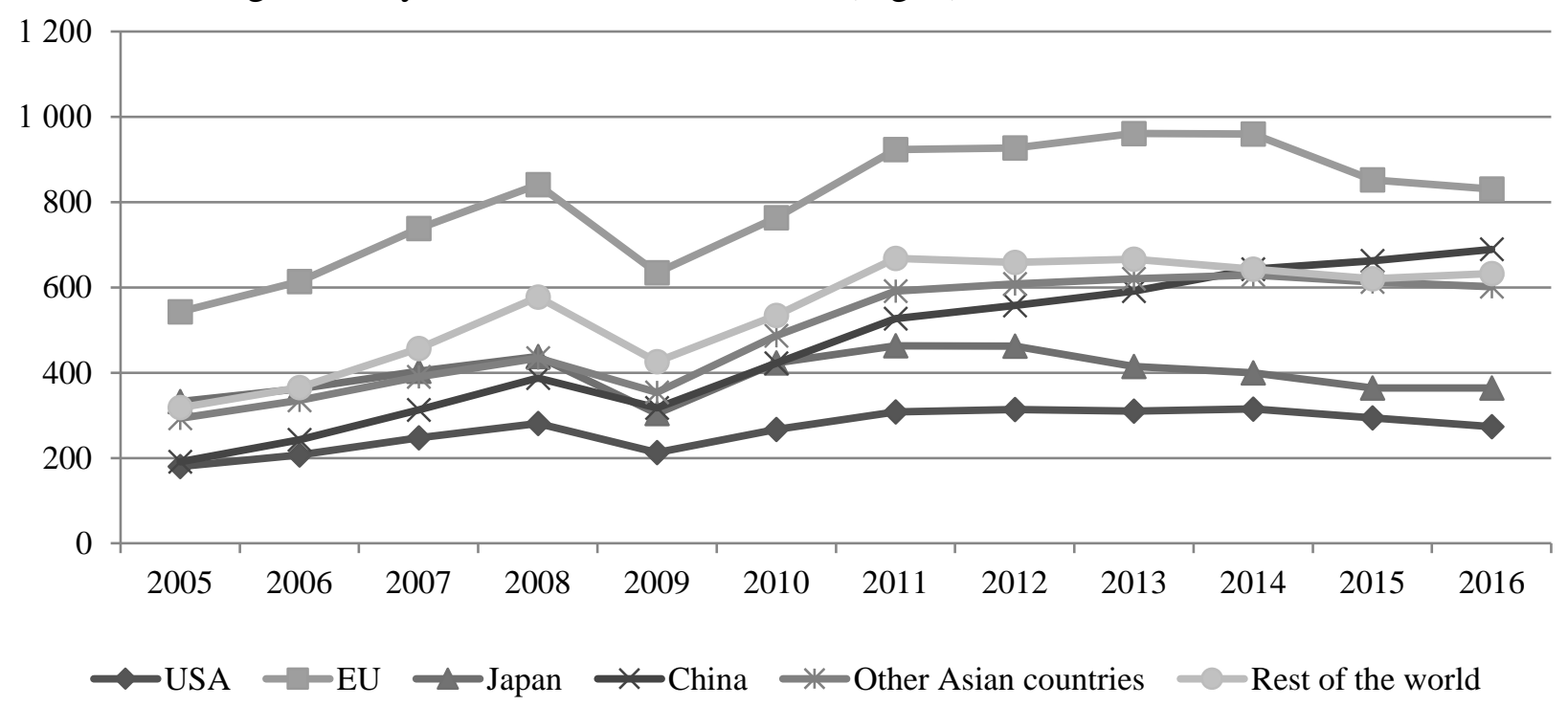

Figure 4. Export of medium-high-tech product, by selected regions, countries, economies: 2005-16, billion dollars (Science..., 2018)

The total volume of medium-high-tech products in global trade flows is steadily increasing and while in 2005, the global export volume of this kind of production was almost $\$ 2$ trillion, then in 2016 , it was more than $\$ 3$ trillion. At the same time, China in terms of exports showed a $25 \%$ lag of the United States in 2005 and twice as high as the US in 2016. As for imports, the United States retains global leadership and focuses on the accumulation of intellectual capital and the tangible results of intellectual activity. 
On the whole, there is a steady increase in trade in knowledgeable products and services: hightech products, medium-high-tech products, knowledge-intensive services. Growth is not only natural indicators, but also relative ones: as a share of overall trade, which indicates the growth of their role in production, and, accordingly, reorientation of production to other technologies (Fig. 5)

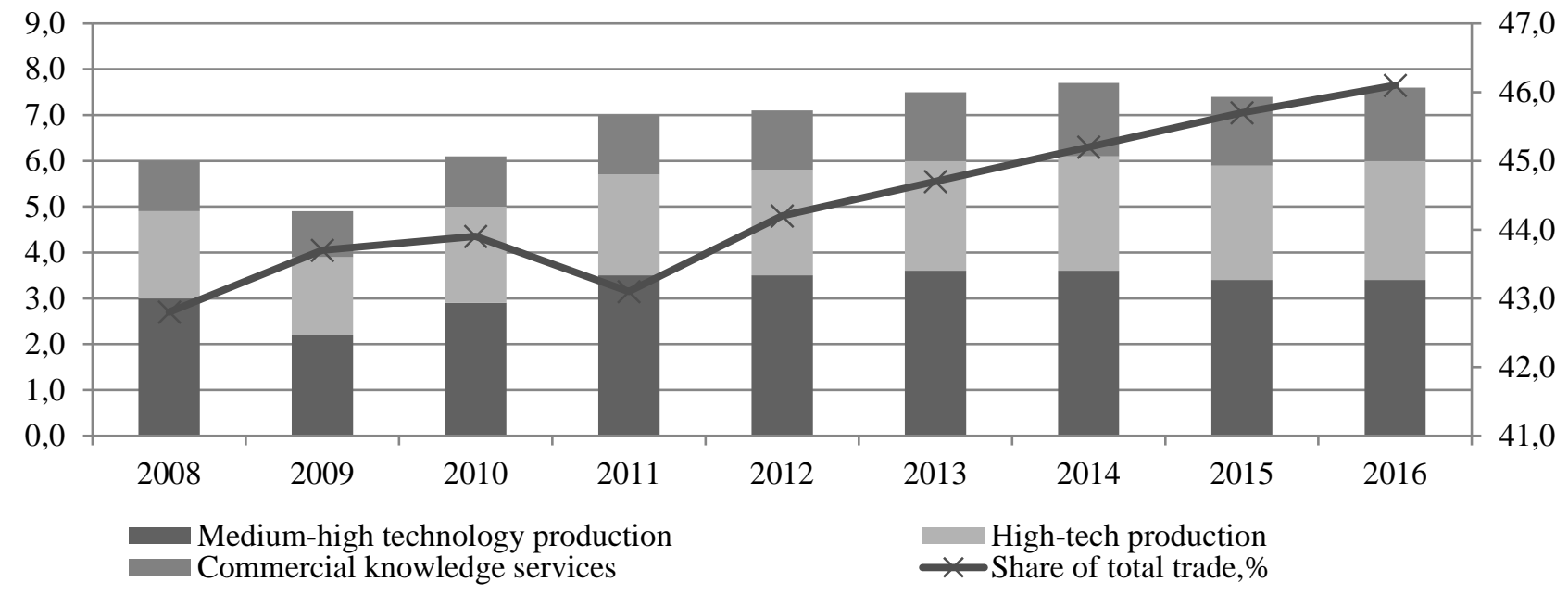

Figure 5. Global export of commercial knowledge of high-volume products and services: 2008-16 trillion dollars (Patterns and..., 2018)

As can be seen from Figure 10, we can note the gradual increase in the share of commercial knowledgeable services, which often accompany high-tech products. There is certain redistribution between the designated groups of goods, as well as the commodity modification of the market structure of high-tech goods in general. In general, high-tech exporting countries also have a high level of R\&D spending, which is sometimes ten times higher than the costs of competitors. At the same time, developed countries allocate financing mainly for improvement of existing technologies and the development of breakthrough innovations. At the same time, less developed countries should focus on the initial stages of development.

The cost of labor is lower than that of highly developed countries, which can serve as a competitive advantage and facilitate the transfer of productions from developed countries to developing countries. For example, China is actively promoting its own outsourcing on the market of high-tech products (Global..., 2016). Each of the leading countries specializes in own production of goods (Achieng..., 2017). Finland specializes in biotechnology, energy and environmental sciences. China is developing robotics, semiconductors, high-speed trains, supercomputers, automobiles and genetic engineering. Canada focuses on biotechnology, wireless interactive machines, supersonic technologies and chips. The United Kingdom is actively developing military technology and unmanned aerial vehicles. Military projects are also being developed by Russia. Germany is developing biotechnology, automotive and mechanical engineering. Israel is one of the five countries focused on the development of space technology. South Korea specializes in robotics. The United States has a wide range of scientific interests: the space industry, nuclear technology, pharmaceuticals, defense systems, telecommunications, and internet technologies. Japan also has a broad specialization: robotics, automotive, electronics, mechanical engineering, space engineering, optics, industrial robotics, biotechnology, metals and semiconductors (Allouche..., 2017).

An important trend in modern development is the formation of a global innovation space, evidenced by the growing volume of scientific cooperation between parties from different countries. The data in the following table characterizes the dynamics of patents obtained as a result of cooperation between countries in conducting innovation activities (Table 1): 
Table 1. Patents in co-operation with foreign companies, 2005-2013 (International..., 2017)

\begin{tabular}{|c|c|c|c|c|c|c|}
\hline & & 2005 & 2010 & 2011 & 2012 & 2013 \\
\hline \multirow{5}{*}{ 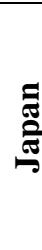 } & Total Patents & 22698,0 & 22367,0 & 22280,0 & 21554,0 & 20081,0 \\
\hline & $\begin{array}{l}\text { General cooperation with } \\
\text { foreign countries }\end{array}$ & 792,0 & 625,0 & 620,0 & 602,0 & 554,0 \\
\hline & Japan & & & & & \\
\hline & USA & 336,0 & 240,0 & 230,0 & 275,0 & 217,0 \\
\hline & EU-28 & 348,0 & 303,0 & 267,0 & 236,0 & 228,0 \\
\hline \multirow{5}{*}{ 芯 } & Total Patents & 40381,0 & 33450,0 & 35668,0 & 37320,0 & 40707,0 \\
\hline & $\begin{array}{l}\text { General cooperation with } \\
\text { foreign countries }\end{array}$ & 5327,0 & 5054,0 & 5359,0 & 5599,0 & 5558,0 \\
\hline & Japan & 336,0 & 240,0 & 230,0 & 275,0 & 217,0 \\
\hline & USA & & & & & \\
\hline & EU-28 & 3206,0 & 2721,0 & 2936,0 & 2995,0 & 2894,0 \\
\hline \multirow{5}{*}{ 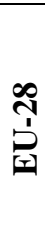 } & Total Patents & 60391,0 & 59824,0 & 60729,0 & 60219,0 & 60140,0 \\
\hline & $\begin{array}{l}\text { General cooperation with } \\
\text { foreign countries }\end{array}$ & 5836,0 & 5475,0 & 5734,0 & 5862,0 & 5681,0 \\
\hline & Japan & 348,0 & 303,0 & 267,0 & 236,0 & 228,0 \\
\hline & USA & 3206,0 & 2721,0 & 2936,0 & 2995,0 & 2894,0 \\
\hline & EU-28 & 3270,0 & 3477,0 & 3508,0 & 3358,0 & 3274,0 \\
\hline \multirow{5}{*}{$\begin{array}{l}\vec{\pi} \\
\overline{0}\end{array}$} & Total Patents & 136759,0 & 133510,0 & 136712,0 & 138839,0 & 141719,0 \\
\hline & $\begin{array}{l}\text { General cooperation with } \\
\text { foreign countries }\end{array}$ & 10960,0 & 11112,0 & 11562,0 & 11741,0 & 11572,0 \\
\hline & Japan & 792,0 & 625,0 & 620,0 & 602,0 & 554,0 \\
\hline & USA & 5327,0 & 5054,0 & 5359,0 & 5599,0 & 5558,0 \\
\hline & EU-28 & 8455,0 & 8308,0 & 8628,0 & 8638,0 & 8377,0 \\
\hline
\end{tabular}

Among the leading patent countries, the United States alone shows the growth of the total number of patents by $1 \%$, while the number of patents in cooperation increased by $4 \%$. In contrast, the EU has contracted by $1 \%$, but the number of patents has grown significantly, which is the result of cooperation between EU countries.

\section{Conclusions}

In general, analyzing performance indicators, we can note that the list of leader countries is not constant; it is constantly changing, which is a sign of fierce competition both between key players and new persistent outsider countries. The results of the analysis show that the United States remain the absolute leader in most of the indicators (9 indicators). Japan and Germany are the leaders in six indices, South Korea, the United Kingdom, China and France - in five, Switzerland and Canada - in four. At the same time, advanced countries show quite different rates and trends in the dynamics of change in key indicators of their intellectual activity, which is reflected in the high volatility of countries' positions. All this gives grounds for predicting further transformations in the list of global intellectual leaders.

\section{References}

Academic Ranking of World Universities (2017). Retrieved from - http://www.shanghairanking.com/ARWUStatistics-2017.html [2020 08 01]

Achieng Vivian (2017). Top 15 Most High-Tech Countries In The World. Retrieved from https://www.therichest.com/technologies/top-15-most-high-tech-countries-in-the-world/ [2020 08 21]

Allouche D. (2017) Top 10 of the Most High Tech Countries in the World. Retrieved from - https://www.youngdiplomats.com/top-10-high-tech-countries-world/ [2020 08 03]

Global High Tech Exports by Country (2016). Retrieved from - https://www.worldatlas.com/articles/countrieswith-the-most-high-tech-exports.html [2020 08 03] 
High-technology exports (\% of manufactured exports), selected countries (2016). Retrieved from http://databank.worldbank.org/data/source/world-development-indicators\# [2020 07 12]

Industrial design applications, resident, by count (2016). Retrieved from - http://databank.worldbank.org/ data/source/world-development-indicators\# [2020 08 21]

International co-operation in patents (2017). Retrieved from - https://stats.oecd.org/Index.aspx? DataSetCode= PATS_COOP [2020 08 01]

List of Nobel laureates by university affiliation (2017). Retrieved from - https:/www.nobelprize.org/prizes/ lists/all-nobel-prizes/ [2020 08 05]

Number of publications in reviewed journals (2016). Retrieved from - http://databank.worldbank.org/data/source world-development-indicators\# [2020 08 14]

Patent applications, residents and nonresidents (2016). Retrieved from - http://databank.worldbank.org/data /source/world-development-indicators\# [2020 09 17]

Patents by country (2016). Retrieved from - http://databank.worldbank.org/data/source/world-developmentindicators\# [2020 08 01]

Patterns and trends of knowledge and technology intensive industries (2018). Retrieved from https://www.nsf.gov/statistics/2018/nsb20181/report/sections/industry-technology-and-the-global-marketplace/patternsand-trends-of-knowledge--and-technology-intensive-industries [2020 08 22]

Science and Engineering Indicators (2018). Retrieved from https://www.nsf.gov/statistics/2018/nsb20181/report/sections/industry-technology-and-the-global-marketplace/patternsand-trends-of-knowledge--and-technology-intensive-industries [2020 09 21]

TOP-30 countries with Nobel prize winners (2017). Retrieved from - https://www.worldatlas.com/articles/top-30countries-with-nobel-prize-winners.html [2020 09 11]

Trade balance of HT products, by selected region, country, or economy (2018). Retrieved from https://www.nsf.gov/statistics/2018/nsb20181/report/sections/industry-technology-and-the-global-marketplace/patternsand-trends-of-knowledge--and-technology-intensive-industries\#global-trends-in-medium-high-technology-industries [2020 09 13]

Trademark applications (2017). Retrieved from - http://databank.worldbank.org/data/source/world-developmentindicators\# [2020 09 14]

World University Rankings (2018). Retrieved from - https://www.timeshighereducation.com/world-universityrankings/2018/world-ranking\#!/page/0/length/-1/sort_by/rank/sort_order/asc/cols/stats [2020 0911$]$

ICT development index. Retrieved from - http://www.itu.int/net4/ITU-D/idi/2017/index.html [2020 09 12] 